\title{
Transient receptor potential canonical 1 channel mediates the mechanical stress-induced epithelial-mesenchymal transition of human bronchial epithelial (16HBE) cells
}

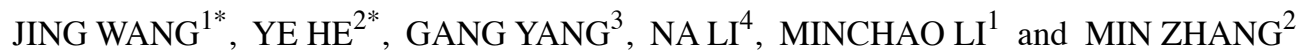 \\ ${ }^{1}$ Department of Respiratory Medicine, The Second Clinical Hospital of Chongqing Medical University, \\ Chongqing 400010; ${ }^{2}$ Department of Geriatrics, Sichuan Provincial People's Hospital, \\ Sichuan Academy of Medical Science, Chengdu, Sichuan 610072; ${ }^{3}$ Department of Neurosurgery, \\ The First Clinical Hospital of Chongqing Medical University, Chongqing 400016; ${ }^{4}$ Division of Nephrology, \\ The Seventh Affiliated Hospital, Sun Yat-sen University, Shenzhen, Guangdong 518107, P.R. China
}

Received November 16, 2019; Accepted March 17, 2020

DOI: $10.3892 /$ ijmm.2020.4568

\begin{abstract}
Airway remodeling is a central event in the pathology of chronic obstructive pulmonary disease (COPD) that leads to airway narrowing and subsequently, to increased mechanical pressure. High mechanical pressure can exacerbate airway remodeling. Thus, a treatment regimen aimed at disrupting this high-pressure airway remodeling vicious cycle may improve the prognosis of patients with COPD. Recent studies have demonstrated that mechanical stress induces lung
\end{abstract}

Correspondence to: Professor Minchao Li, Department of Respiratory Medicine, The Second Clinical Hospital of Chongqing Medical University, 74 Linjiang Road, Yuzhong, Chongqing 400010, P.R. China

E-mail: liminc66@aliyun.com

Professor Min Zhang, Department of Geriatrics, Sichuan Provincial People's Hospital, Sichuan Academy of Medical Science, 32, Western Section 2nd Part of 1st Ring Road, Chengdu, Sichuan 610072, P.R. China

E-mail: zmzm73@163.com

${ }^{*}$ Contributed equally

Abbreviations: EMT, epithelial-mesenchymal transition; TRPC1, transient receptor potential canonical 1; COPD, chronic obstructive pulmonary disease; ECM, extracellular matrix; MUC5AC, mucin5AC; MscCa, mechanosensitive cation; $\mathrm{Ca}^{2+}$, calcium; HBE, human bronchial epithelial; PIP2, phosphatidylinositol-4,5-bisphosphate; PKC, protein kinase $\mathrm{C}$; BAPTA-AM, 1,2-bis(2-aminophenoxy)ethane-N,N,N',N'-tetraacetic acid; GOLD, Global Initiative for Chronic Obstructive Lung Disease; FEV1, forced expiratory volume in the first second; FVC, forced vital capacity

Key words: mechanical stress, airway remodeling, transient receptor potential canonical 1, epithelial-mesenchymal transition, chronic obstructive pulmonary disease epithelial-mesenchymal transition (EMT), which is commonly present in airway epithelial cells of patients with COPD. As TRPC1 functions as a mechanosensitive channel that mediates non-selective cation entry in response to increased membrane stretch, the present study investigated the role of TRPC1 in the occurrence of EMT induced by mechanical stress. In the present study, the expression of TRPC1 in the bronchial epithelium was examined in vivo by immunohistochemistry. In vitro, human bronchial epithelial (16HBE) cells were subjected to mechanical stretching for up to $48 \mathrm{~h}$, and TRPC1 expression was then examined by RT-qPCR and western blot analysis. In addition, TRPC1 receptor function was assessed by $\mathrm{Ca}^{2+}$ imaging and siRNA transfection. EMT was identified using immunofluorescence, western blot analysis and RT-qPCR. It was found that TRPC1 expression was upregulated in patients with COPD and in 16HBE cells subjected to mechanical stretch. The mechanical stress-induced activation of TRPC1 in 16HBE cells increased the intracellular calcium concentration and subsequently decreased the expression of cytokeratin 8 and E-cadherin, and increased the expression of $\alpha$-smooth muscle actin, indicating the occurrence of EMT. On the whole, the findings of the present study demonstrate that TRPC1 plays a key role in the occurrence of EMT in human lung epithelial cells in response to mechanical stretch; thus, this protein may serve as a novel therapeutic target for progressive airway remodeling in COPD.

\section{Introduction}

Cells and the extracellular matrix (ECM) in the airways are subjected to various mechanical stimuli, such as the continuous cyclic stretch of breathing and the contraction of the airway smooth muscle, due to the dynamic nature of lung function (1). Pathologically high levels of stretch exerted on lung tissues play a key role in many pathological situations. This process can induce the expression of various inflammatory mediators, including interleukin (IL)-6, tumor necrosis factor (TNF)- $\alpha$, IL-13 and matrix metalloproteinase (MMP-9) $(2,3)$, and an increase in goblet cell number and mucin5AC (MUC5AC) 
protein secretion (4,5). Furthermore, excessive stretching is a major cause of airway remodeling $(2,6-8)$. Over the past few years, extensive research has been conducted to investigate the role of abnormal mechanical stress in airway remodeling in asthma; however, very little attention has been devoted to stress-induced airway remodeling in chronic obstructive pulmonary disease (COPD), which is characterized by chronic coughing, sputum production and recurrent episodes of wheezing that result in the pathological upregulation of airway pressure.

Airway remodeling is a critical feature of COPD, characterized by the aberrant repair of the epithelium and the accumulation of fibroblasts, which contribute to ECM deposition, leading to irreversible airway obstruction and progressive high pressure in the airways $(9,10)$. Thus, airway remodeling and increased airway mechanical stress function in a vicious cycle that may contribute to the ongoing decline in lung function and quality of life and, ultimately, the poor prognosis of patients with COPD. Thus, further elucidation of the mechanisms of mechanical stress-induced airway remodeling in COPD is important for the treatment of this disease.

Recently, epithelial-mesenchymal transition (EMT) has been identified as a new source of fibroblasts that can contribute to the remodeling of the airways (11). EMT is a biological process that allows a polarized epithelial cell with cell-cell contacts that is attached to the basal membrane to acquire the characteristics of mesenchymal cells through multiple biochemical alterations $(12,13)$. Significant EMT has been demonstrated in the airway epithelial cells of patients with COPD (14-16), and EMT has been suggested as an important factor for airway remodeling in COPD $(17,18)$. Previous studies have demonstrated that primary airway epithelial cells subjected to mechanical stretch acquire EMT phenotypes (19-21). However, the specific molecular mechanisms of EMT in response to mechanical stress remain poorly understood.

Transient receptor potential canonical 1 (TRPC1), a member of the vertebrate mechanosensitive cation $(\mathrm{MscCa})$ channels, plays a critical role in converting the sensed mechanical stimuli into biological signals by transuding stretch into $\mathrm{Ca}^{2+}$ flux across the cell membrane $(22,23)$. TRPC1 has been reported to be abundantly expressed in airway epithelial cells and its expression is markedly increased in patients with COPD (18). Furthermore, the recent study by Xu et al indicated that the increase in TRPC1 expression was closely related to the occurrence of EMT in patients with COPD where they exposed human bronchial epithelial (HBE; 16HBE cells) to $5 \%$ cigarette smoking extract (CSE) (18). Therefore, it was hypothesized that TRPC1 plays a vital role in the process of mechanical stress-induced airway remodeling in COPD via the occurrence of EMT. To test this hypothesis, in vivo, the present study examined the expression of TRPC1 in patients with COPD. In vitro, $16 \mathrm{HBE}$ cells we exposed to mechanical stretch for up to $48 \mathrm{~h}$ to mimic the effects of high airway pressure, and TRPC1 expression was then measured by RT-qPCR and western blot analysis. The function of TRPC1 was assessed by $\mathrm{Ca}^{2+}$ imaging and siRNA transfection, and the occurrence of EMT was identified by immunofluorescence, western blot analysis and RT-qPCR. It was that TRPC1 expression was upregulated in patients with COPD and in 16HBE cells subjected to mechanical stretch. The TRPC1-mediated increase in intracellular $\mathrm{Ca}^{2+}$ played a key role in the occurrence of EMT in human lung epithelial cells in response to mechanical stretch. Thus, this molecule may serve as a novel therapeutic target for progressive airway remodeling in COPD.

\section{Materials and methods}

Reagents. 16HBE cells were purchased from the American Type Culture Collection (ATCC). Lipofectamine RNAiMAX reagent was obtained from Invitrogen; Thermo Fisher Scientific, Inc. Rabbit polyclonal anti-TRPC1 antibody (ab75322) was purchased from Abcam. Mouse monoclonal anti-cytokeratin 8 (sc-58736) and E-cadherin (sc-8426) antibodies were purchased from Santa Cruz Biotechnology, Inc. Rabbit anti- $\alpha$-smooth muscle actin ( $\alpha$-SMA) monoclonal antibodies (ab32575) were purchased from Abcam. Rabbit monoclonal anti-GAPDH antibody (AF1186) was from Beyotime Institute of Biotechnology. Cy3-labeled goat anti-mouse antibodies (A0521) and FITC-labeled goat anti-rabbit antibodies (A0562) were purchased from Beyotime Institute of Biotechnology. TRPC1 and NC siRNAs were purchased from Ribo Biotechnology Co, Ltd. SYBR Premix EX Taq was purchased from Takara Biotechnology. The bicinchoninic acid (BCA) assay kit and Fluro-3 AM were purchased from Beyotime Institute of Biotechnology, and TRIzol reagent was purchased from Invitrogen; Thermo Fisher Scientific, Inc. The PCR primers for TRPC1, GAPDH, cytokeratin 8 , E-cadherin and $\alpha$-SMA were from Sangon Biotech. The Revert Aid First Strand cDNA synthesis kits were purchased from Fermentas; Thermo Fisher Scientific, Inc. 3,3'-Diaminobenzidine tetrahydrochloride (DAB) was from Sigma-Aldrich; Merck KGaA; 1,2-bis(2-aminophenoxy) ethane-N,N,N',N'-tetraacetic acid (BAPTA-AM) was purchased from Santa Cruz Biotechnology, Inc. ECL reagent was from Beyotime Institute of Biotechnology.

Tissue samples. Normal human lung tissues were obtained from surgical specimens that were resected in the Department of Thoracic Surgery, the 2nd Clinical Hospital of Chongqing Medical University from 2014 to 2015 . The test population consisted of 20 patients who were pathologically diagnosed with stage I non-small cell lung cancer (NSCLC) according to the 8th edition of the TNM classification for lung cancer. All patients were informed of the research content of the project and signed an agreement to participate in the present study. Ethics committee approval was obtained for the Second Clinical Hospital of Chongqing Medical University. None of the patients had a history of any disease other than COPD and lung cancer. All the normal lung tissues that were obtained from the organization were separated from the tumor by at least $5 \mathrm{~cm}$ and were examined by a pathologist to confirm that they were non-cancerous. The subjects were divided into the COPD group ( 8 males, 5 females) with a mean age of 58.7 years (SD, 3.9 years) and the control group (4 males, 3 females) with a mean age of 60.4 years (SD, 5.4 years). The diagnosis of COPD was based on the Global Initiative for Chronic Obstructive Lung Disease (GOLD) criteria (24) namely a post bronchodilator FEV1/FVC $<0.7$ [forced expiratory volume in the first second (FEV1); forced vital capacity 
(FVC)] with a history of long-term cigarette smoking or significant biomass exposure. According to the GOLD criteria, the patients with COPD were defined as stage I COPD (FEV1 $>80 \%$ of the predicted value, $\mathrm{n}=8)$ and stage II COPD $(50<$ FEV1 $>80 \%, n=5)$. None of the patients with COPD were classified as GOLD stage III or GOLD stage IV. The control group exhibited no underlying chronic inflammatory airway disease. Patients with COPD were more likely to be smokers (COPD vs. control, 10/13 vs. 2/7) and had more pack-years of smoking (COPD vs. control, $37.11 \pm 6.53$ vs. $9.81 \pm 1.21$ ) than control. The resected tissues were then immediately frozen in liquid nitrogen. Human bronchi were analyzed using immunohistochemistry, and each bronchial mucosa was evaluated by western blot analysis and RT-qPCR.

Immunohistochemical localization of TRPC1 in human lung tissues. Human lung tissues were immunohistochemically stained to assess the protein expression of TRPC1. The tissues were fixed with formalin, embedded in paraffin, and cut into $5-\mu$ m-thick serial sections. Endogenous peroxide activity was quenched using $3 \% \mathrm{H}_{2} \mathrm{O}_{2}$, and non-specific binding was minimized by incubating the tissues in $1 \%$ normal goat serum. The sections were then incubated at room temperature with rabbit anti-TRPC1 polyclonal antibody at a final dilution of 1:200 for $1 \mathrm{~h}$. This step was followed by incubation with goat anti-rabbit biotinylated secondary antibodies (1:200 dilution) for $30 \mathrm{~min}$ at $37^{\circ} \mathrm{C}$ and incubation with a solution of streptavidin-peroxidase complexes at a dilution of 1:100 for $45 \mathrm{~min}$. Finally, color reactions were developed using the chromogen DAB. Five fields were randomly selected for the slices observed under a light microscope (Olympus Corp.). The dark brown cells were regarded as positive cells. Image-Pro Plus 6.0 software (MediaCybernetics) was employed to detect the staining intensity for further analysis.

Cell culture and grouping. The 16HBE cells were cultured in RPMI-1640 medium containing 10\% fetal bovine serum and incubated at $37^{\circ} \mathrm{C}$ in a humidified water-jacketed incubator containing $95 \%$ air and $5 \% \mathrm{CO}_{2}$ during the subsequent experiments. Cultured cells were divided into a control group and a group exposed to mechanical stretch. Cells in the control group were cultured on similar plates in the same incubator without any additional intervention, whereas cells in the mechanical stretch group were subjected to sinusoidal stretching for $48 \mathrm{~h}$ at a frequency of 60 cycles per min at a $15 \%$ elongation using a FX-4000 Flexcell tension system (Flexcell International Corp.) (please see the mechanical stretch system section below for more details). Inhibition experiments were performed by transfection of the 16HBE cells with TRPC1 siRNA/NC siRNA or by the addition of the intracellular calcium chelator, 1,2-bis(2-aminophenoxy)ethane-N,N,N',N'-tetraacetic acid (BAPTA-AM).

Transient transfection with TRPCl siRNA. The $16 \mathrm{HBE}$ cells were plated into 6 -well plates at 200,000 cells per well in medium containing $10 \%$ fetal bovine serum and incubated overnight. The cells were then cultured in serum-free medium before being divided into 3 groups as follows: The control group, the TRPC1 siRNA group and the NC siRNA group. A total of 100 pmol TRPC1 siRNA or NC siRNA were transfected into the 16HBE cells using Lipofectamine RNAiMAX reagent (10:1) according to the manufacturer's instructions. The detailed sequence of TRPC1 siRNA and NC siRNA are shown as follows: TRPC1 siRNA sense, 5'-GGA UGUGCGGGAGGUGAAGtt-3' and antisense, 5'-CUUCAC CUCCCGCACAUCCtt-3'; NC siRNA sense, 5'-UUCUCC GAACGUGUCACGUTT-3' and antisense, 5'-ACGUGACAC GUUCGGAGAATT-3'. At $6 \mathrm{~h}$ following transfection, the cells were fed with medium containing $10 \%$ fetal bovine serum and incubated at $37^{\circ} \mathrm{C}$ for a further $48 \mathrm{~h}$. RT-qPCR and western blot analysis were then performed to determine the efficiency of TRPC1 knockdown.

Mechanical stretch system. In the in vitro experiments, a FX-4000 Flexcell tension system (Flexcell International Corp.) was used to apply sinusoidal strain to the 16HBE cells as previously described $(2,8)$ to imitate the pathological conditions that are associated with airway mechanical stress. Briefly, the $16 \mathrm{HBE}$ cells were first separately seeded at $4 \times 10^{5}$ cells/well in Flexcell biaxial 6-well plates coated with type I collagen (Flexcell International Corp.) in medium containing 10\% fetal bovine serum for $24 \mathrm{~h}$ before it was replaced with serum-free medium. The cells were then divided into a control group and a group exposed to mechanical stretch. Cells in the control group were cultured on similar plates in the same incubator without any additional intervention, including mechanical loading, whereas cells in the mechanical stretch group were subjected to sinusoidal stretching for $48 \mathrm{~h}$ at a frequency of 60 cycles per min at a $15 \%$ elongation.

$\mathrm{Ca}^{2+}$ imaging was used to measure the activation of TRPC1 in $16 \mathrm{HBE}$ cells after the cells were exposed to sinusoidal stretching for $0.5,1,2,4,8,12,24$ and $48 \mathrm{~h}$. After the cells had been stretched for $48 \mathrm{~h}$ at a $15 \%$ elongation, western blot analysis, immunofluorescence and RT-qPCR were performed to determine the protein and mRNA expression profiles of EMT-related genes. Inhibition experiments were performed with $16 \mathrm{HBE}$ cells transfected with TRPC1 siRNA/NC siRNA.

$\mathrm{Ca}^{2+}$ imaging. The levels of intracellular $\mathrm{Ca}^{2+}$ were measured using the membrane- and cell-permeable $\mathrm{Ca}^{2+}$-indicator, Fluo-3-AM. Following mechanical stretching, 16HBE cells were seeded into confocal dishes at a density of 1,000,000 cells per dish. After the cells were washed 3 times with PBS, they were incubated with PBS containing $3 \mathrm{mmol} / 1$ of Fluo-3-AM for $45 \mathrm{~min}$ at $37^{\circ} \mathrm{C}$. The cells were then washed 3 times with modified Krebs-Ringer HEPES buffer and incubated at $37^{\circ} \mathrm{C}$ for a further $30 \mathrm{~min}$ prior to analysis. Images were collected and analyzed at multiple time points with a laser scanning confocal microscope system (TCSSP2, Leica Microsystems $\mathrm{GmbH}$ ). The fluorescence intensity was analyzed with the quantification tools available in the confocal microscope software.

$R T-q P C R$. The mRNA levels of TRPC1, cytokeratin 8, E-cadherin and $\alpha$-SMA were measured by RT-qPCR. TRIzol reagent was used to extract total RNA from the cultured $16 \mathrm{HBE}$ cells according to the manufacturer's instructions. A total of $5 \mu \mathrm{g}$ total RNA was reverse transcribed into complementary DNA (cDNA) with a first-strand cDNA synthesis kit. The specific primer sequences for RT-qPCR were as follows: 
TRPC1 sense, 5'-TCGTGGTTGTGATTGTGCTT-3' and antisense, 5'-TGGTGAGGGAATGATGTTGA-3'; GAPDH sense, 5'-AGAAGGCTGGGGCTCATTTG-3' and antisense, 5'-AGG GGCCATCCACAGTCTTC-3'; cytokeratin 8 sense, 5'-GAG GCATCACCGCAGTTAC-3' and antisense, 5'-TTGCTTCGA GCCGTCTTCT-3'; E-cadherin sense, 5'-GCCAAAGACAGA GCGGAACTAT-3' and antisense, 5'-ATGTGTTCAGCTCAG CCAGC-3'; and $\alpha$-SMA sense, 5'-CCGACCGAATGCAGA AGGA-3' and antisense, 5'-ACAGAGTATTTGCGCTCC GAA-3'. The PCR reaction was performed for 35 cycles under the following conditions: Pre-denaturation at $94^{\circ} \mathrm{C}$ for $2 \mathrm{~min}$; denaturation at $94^{\circ} \mathrm{C}$ for $30 \mathrm{sec}$, annealing at $60^{\circ} \mathrm{C}$ (TRPC1 and $\alpha$-SMA), $65^{\circ} \mathrm{C}$ (cytokeratin 8 ), or $58^{\circ} \mathrm{C}$ (E-cadherin) for $30 \mathrm{sec}$ and extension at $72^{\circ} \mathrm{C}$ for $10 \mathrm{~min}$. The comparative $\mathrm{Cq}$ method $\left(2^{-\Delta \Delta C q}\right)(25)$ was used to determine the relative mRNA quantification, and GAPDH was used as the endogenous control gene.

Western blot analysis. First, the 16HBE cells were homogenized on ice in RIPA lysis buffer containing protease inhibitors. After the mixture was centrifuged at $11,000 \mathrm{rpm}$ for $10 \mathrm{~min}$ at $4^{\circ} \mathrm{C}$, the supernatant was used for western blot analysis. The total protein was assessed using a BCA protein assay. Equivalent amounts of protein $(30 \mu \mathrm{g})$ were obtained from each sample and fractionated using 10\% SDS-PAGE. The blots were then transferred onto polyvinylidene fluoride membranes. The membranes were blocked in skim milk for $1 \mathrm{~h}$ at room temperature and then incubated overnight at $4^{\circ} \mathrm{C}$ with rabbit anti-TRPC1 polyclonal antibodies $(1: 1,000)$, mouse anti-cytokeratin 8 monoclonal antibodies $(1: 1,000)$, mouse anti-E-cadherin monoclonal antibodies $(1: 1,000)$, rabbit anti- $\alpha$-SMA monoclonal antibodies $(1: 1,000)$ and rabbit anti-GAPDH monoclonal antibodies $(1: 1,000)$. The membranes were then incubated with the corresponding horseradish peroxidase-conjugated secondary antibodies $(1: 2,000)$ for $1 \mathrm{~h}$ at $37^{\circ} \mathrm{C}$. Finally, the membranes were incubated with western blot ECL reagent in the dark for $5 \mathrm{~min}$. Quantitative results were acquired by measuring the optical density of the labeled bands using Quantity One software (Bio-Rad Laboratories, Inc.). The values were normalized to the intensity level of GAPDH.

Immunofluorescence. First, the 16HBE cells were seeded into 24-well plates at a density of 100,000 cells per well and cultured in medium containing $10 \%$ fetal bovine serum overnight. The cells were then washed 3 times with PBS, fixed with $4 \%$ paraformaldehyde for $20 \mathrm{~min}$ and permeabilized using $0.3 \%$ Triton X-100 for $5 \mathrm{~min}$. After the cells were blocked with goat serum for $1 \mathrm{~h}$ at room temperature, they were incubated with rabbit anti-TRPC1 polyclonal antibodies (1:200), mouse anti-cytokeratin 8 monoclonal antibodies $(1: 100)$, mouse anti-E-cadherin monoclonal antibodies (1:100), or rabbit anti- $\alpha$-SMA monoclonal antibodies (1:500) at $4^{\circ} \mathrm{C}$ overnight. Finally, all the culture dishes were incubated with Cy3-labeled goat anti-mouse antibodies (1:500) and FITC-labeled goat anti-rabbit antibodies (1:500) for $1 \mathrm{~h}$ at $37^{\circ} \mathrm{C}$. The cells were then stained with DAPI $(10 \mathrm{mg} / \mathrm{ml})$ for $15 \mathrm{~min}$. Fluorescent labeling was analyzed using a fluorescence upright microscope (BX51, Olympus Corp.). Fluorescence intensities were evaluated using Image-Pro Plus software (Media Cybernetics).
The results are presented as the fold control of fluorescence intensity.

Statistical analysis. All data are expressed as the means \pm SD. Data analyses were performed using SPSS 22.0 software (IBM Corp.). Statistical analysis was performed using a Student's t-test for comparisons between 2 groups and one-way analysis of variance (ANOVA) followed by Least Significant Difference (LSD) for comparisons involving $>2$ groups. The level of statistical significance was established at $\mathrm{P}<0.05$.

\section{Results}

TRPC1 protein and mRNA levels in bronchial epithelial cells are increased in patients with COPD. The results of immunohistochemistry revealed that the majority of TRPC1 immunoreactivity was localized at the basal surface in epithelial cells (Fig. 1A and B). The value of the integrated optical density/area of the TRPC1 protein in the bronchial epithelium was higher in patients with COPD $(0.246 \pm 0.027)$ than in patients in the control group who had no underlying chronic inflammatory airway disease $(0.161 \pm 0.021, \mathrm{P}=0.012$; Fig. 1C). The results of RT-qPCR and western blot analysis revealed that the TRPC1 mRNA (COPD vs. control, $2.42 \pm 0.702$ vs. $1 \pm 0.00$, $\mathrm{P}<0.001$, Fig. 1D) and protein (COPD vs. control, $1.32 \pm 0.337$ vs. $0.710 \pm 0.164, \mathrm{P}=0.002$, Fig. $1 \mathrm{E}$ and $\mathrm{F}$ ) levels in the lung tissues of patients with COPD were significantly higher than those of the control group.

Transfection with TRPC1 siRNA suppresses TRPC1 protein expression in 16HBE cells. The knockdown efficiency was determined by RT-qPCR and western blot analysis. A significantly lower level of TRPC1 mRNA (control vs. TRPC1 siRNA, $1 \pm 0.00$ vs. $0.378 \pm 0.086, \mathrm{P}<0.001$, Fig. $2 \mathrm{~A}$ ) and protein (control vs. TRPC1 siRNA, $0.930 \pm 0.085$ vs. $0.476 \pm 0.051$, $\mathrm{P}=0.0014$, Fig. $2 \mathrm{~B}$ and $\mathrm{C}$ ) was observed in the $16 \mathrm{HBE}$ cells transiently transfected with TRPC1 siRNA than in the control cells. However, there was no significant difference in the TRPC1 mRNA and protein levels between the NC siRNA transfection group and the control group ( $\mathrm{P}>0.6726$, Fig. 2).

Mechanical stretch upregulates the $m R N A$ and protein expression of TRPC1 levels in 16HBE cells. RT-qPCR and western blot analysis were used to quantify changes in the mRNA and protein levels of TTRPC1 following exposure of the 16HBE cells to cyclic stretch for $48 \mathrm{~h}$. As shown in Fig. 3, significant increases in the mRNA (control vs. stretch, $1 \pm 0.00$ vs. $1.95 \pm 0.343, \mathrm{P}=0.004, \mathrm{Fig} .3 \mathrm{~A}$ ) and protein levels (control vs. stretch, $0.762 \pm 0.111$ vs. $1.13 \pm 0.173, P=0.035$, Fig. $3 B$ and $C$ ) of TRPC1 were observed in the 16HBE cells following exposure to cyclic stretch.

Mechanical stretch activated the TRPC1 channels in16HBE cells. $\mathrm{Ca}^{2+}$ imaging was used to assess TRPC1 function in the 16HBE cells stimulated with cyclic stretch. As shown in Fig. 4A and B, cyclic stretch produced a robust increase in the intracellular $\mathrm{Ca}^{2+}$ of the 16HBE cells. The intracellular $\mathrm{Ca}^{2+}$ levels reached a maximum at approximately $0.5 \mathrm{~h}$ after the cells were exposed to stretch and then declined slowly to a plateau level that was still higher than the baseline level 
A

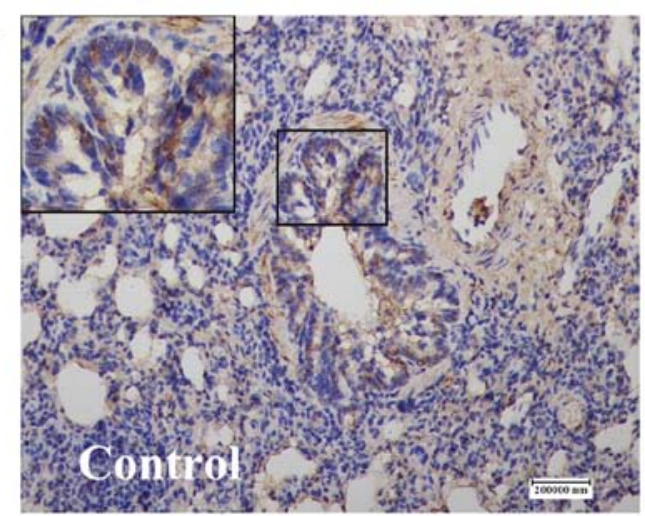

C

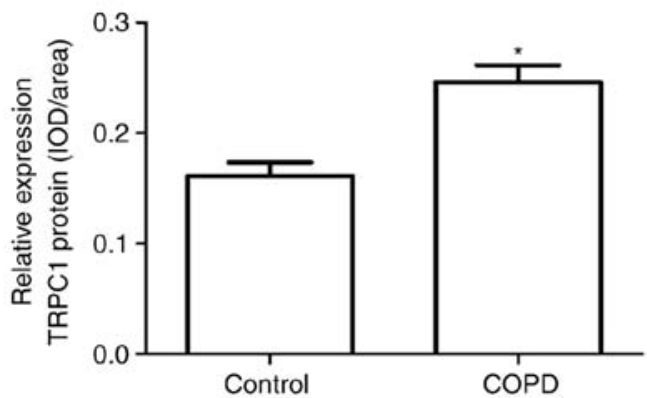

E

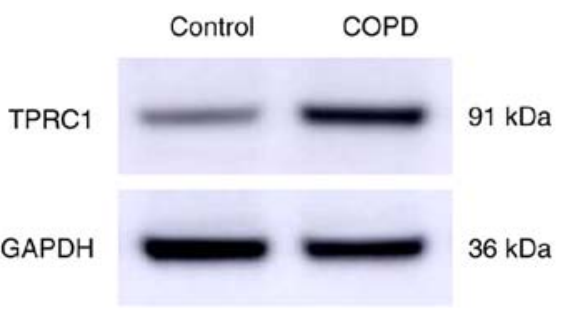

B

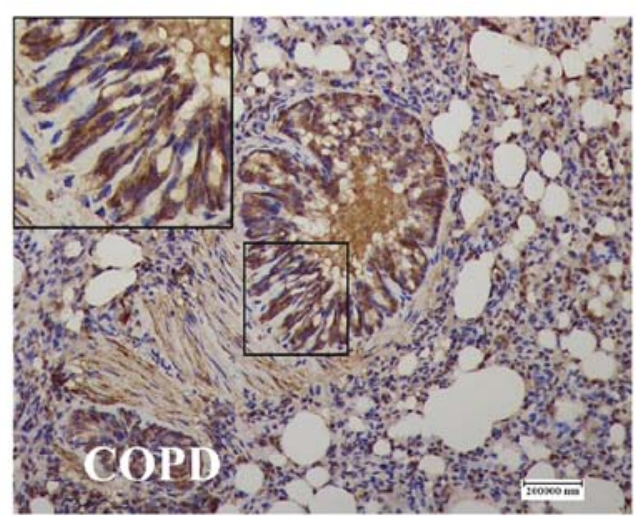

$\mathrm{D}$
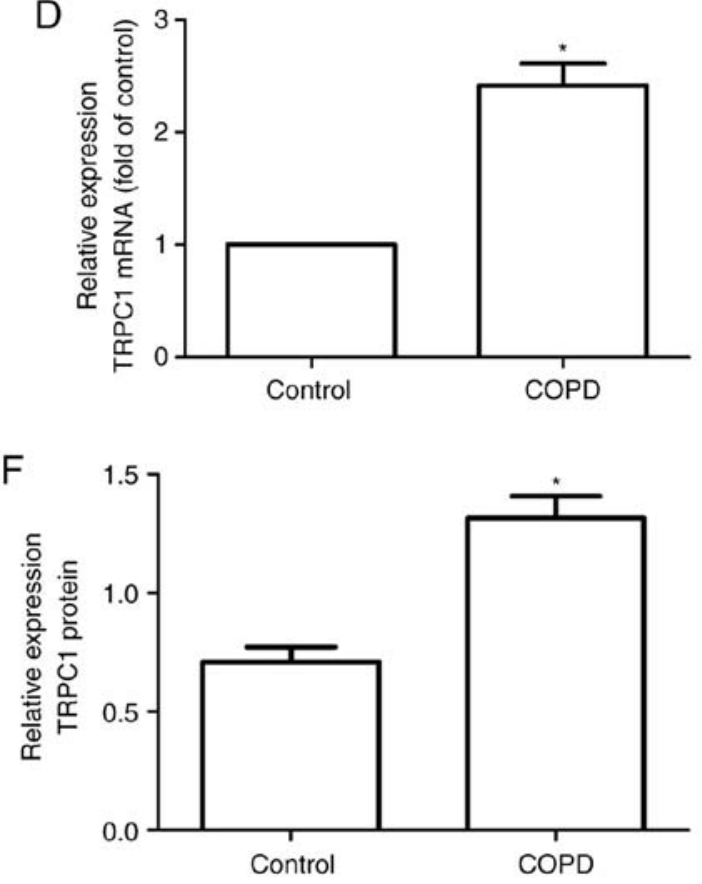

Figure 1. TRPC1 expression in the bronchial epithelium from the COPD $(n=13)$ and control (no chronic inflammatory airway disease, $n=)$ groups was determined by immunohistochemistry, RT-qPCR and western blot analysis. (A and B) TRPC1 protein expression and location in control and COPD groups were assessed in sections by immunohistochemistry (magnification, x200). TRPC1 immunoreactive cells were stained brown by immunohistochemical staining, and were present principally at the basal surface in epithelium. Inset diagram (magnification, $x 400$ ) in the upper left was the enlargement of the box in the main part of the diagram. (C) Immunohistochemistry value of TRPC1 protein in the control and COPD group was quantitatively analyzed using Image-Pro Plus 6.0 software. (D) The mRNA level of TRPC1 was assessed using RT-qPCR. (E and F) The protein level of TRPC1 was assessed by western blot analysis. Values in $(\mathrm{C}, \mathrm{D}$ and $\mathrm{F})$ are shown as the means $\pm \mathrm{SD}$. ${ }^{*} \mathrm{P}<0.05$ vs. the control group.

at approximately $4 \mathrm{~h}$ following stretch initiation. As shown in Fig. 4C and D, the stretch-induced increase in intracellular $\mathrm{Ca}^{2+}$ levels at $48 \mathrm{~h}$ after stretching was substantially attenuated in the $16 \mathrm{HBE}$ cells that were transfected with TRPC1 siRNA (stretch vs. stretch + TRPC1 siRNA, $1.63 \pm 0.205$ vs. $1.08 \pm 0.096, \mathrm{P}=0.03)$, but not in the $16 \mathrm{HBE}$ cells transfected with NC siRNA (stretch vs. stretch + NC siRNA, 1.63 \pm 0.205 vs. $1.56 \pm 0.211, \mathrm{P}=0.572$ ). These results indicated that TRPC1 plays a vital role in mechanical stress-induced increase in intracellular $\mathrm{Ca}^{2+}$ in $16 \mathrm{HBE}$ cells.

Mechanical stretch alters the expression of EMT-related markers in $16 \mathrm{HBE}$ cells. After the $16 \mathrm{HBE}$ cells were exposed to cyclic stretch, changes in the protein expression of lung epithelial cell markers (cytokeratin 8 and E-cadherin) and mesenchymal marker ( $\alpha$-SMA) were observed using immunofluorescence staining, RT-qPCR and western blot analysis.
The results of immunofluorescence staining revealed that the protein levels of cytokeratin 8 (control vs. stretch, $1 \pm 0.00$ vs. $0.335 \pm 0.111, \mathrm{P}<0.001$ ) and E-cadherin (control vs. stretch, $1 \pm 0.00$ vs. $0.345 \pm 0.033, \mathrm{P}<0.001$ ) were significantly decreased after the cells were stretched to $15 \%$ elongation for $48 \mathrm{~h}$ at a frequency of 60 cycles per min, and the protein expression of $\alpha$-SMA (control vs. stretch, $1 \pm 0.00$ vs. $4.71 \pm 0.530, \mathrm{P}<0.001$ ) was increased (Fig. 5A and B). Moreover, the altered fluorescence intensities of cytokeratin 8 , E-cadherin and $\alpha$-SMA induced by mechanical stretch were significantly attenuated by transfection with TRPC1 siRNA (stretch vs. stretch + TRPC1 siRNA, cytokeratin $8,0.335 \pm 0.111$ vs. $1.11 \pm 0.081$, E-cadherin, $0.345 \pm 0.033$ vs. $0.909 \pm 0.008, \alpha$-SMA, $4.71 \pm 0.53$ vs. $1.19 \pm 0.235, \mathrm{P}<0.001)$. RT-qPCR and western blot analysis were used to quantify the changes in the mRNA and protein levels of cytokeratin 8 , E-cadherin and $\alpha$-SMA in the $16 \mathrm{HBE}$ cells following mechanical stretch. As shown in Fig. 5C-E, 

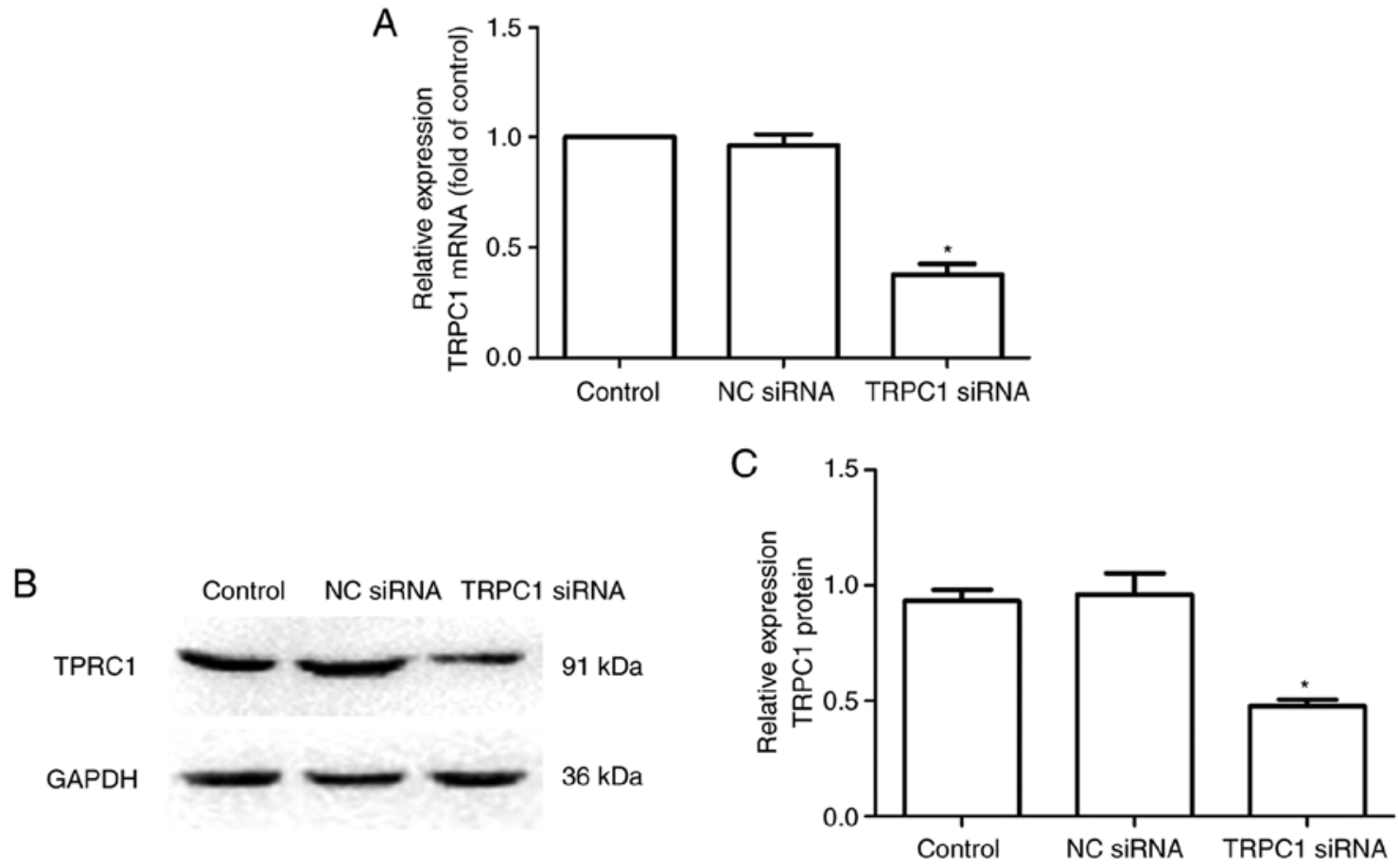

Figure 2. The efficiency of knockdown in TRPC1 expression by TRPC1 siRNA was determined by RT-qPCR and western blot analysis. (A) The level of the TRPC1 mRNA was determined by RT-qPCR. (B and C) The level of TRPC1 protein was determined by western blot analysis. Values in (A and C) are shown as the means $\pm \mathrm{SD}(\mathrm{n}=3)$. ${ }^{*} \mathrm{P}<0.05$ vs. the control group.

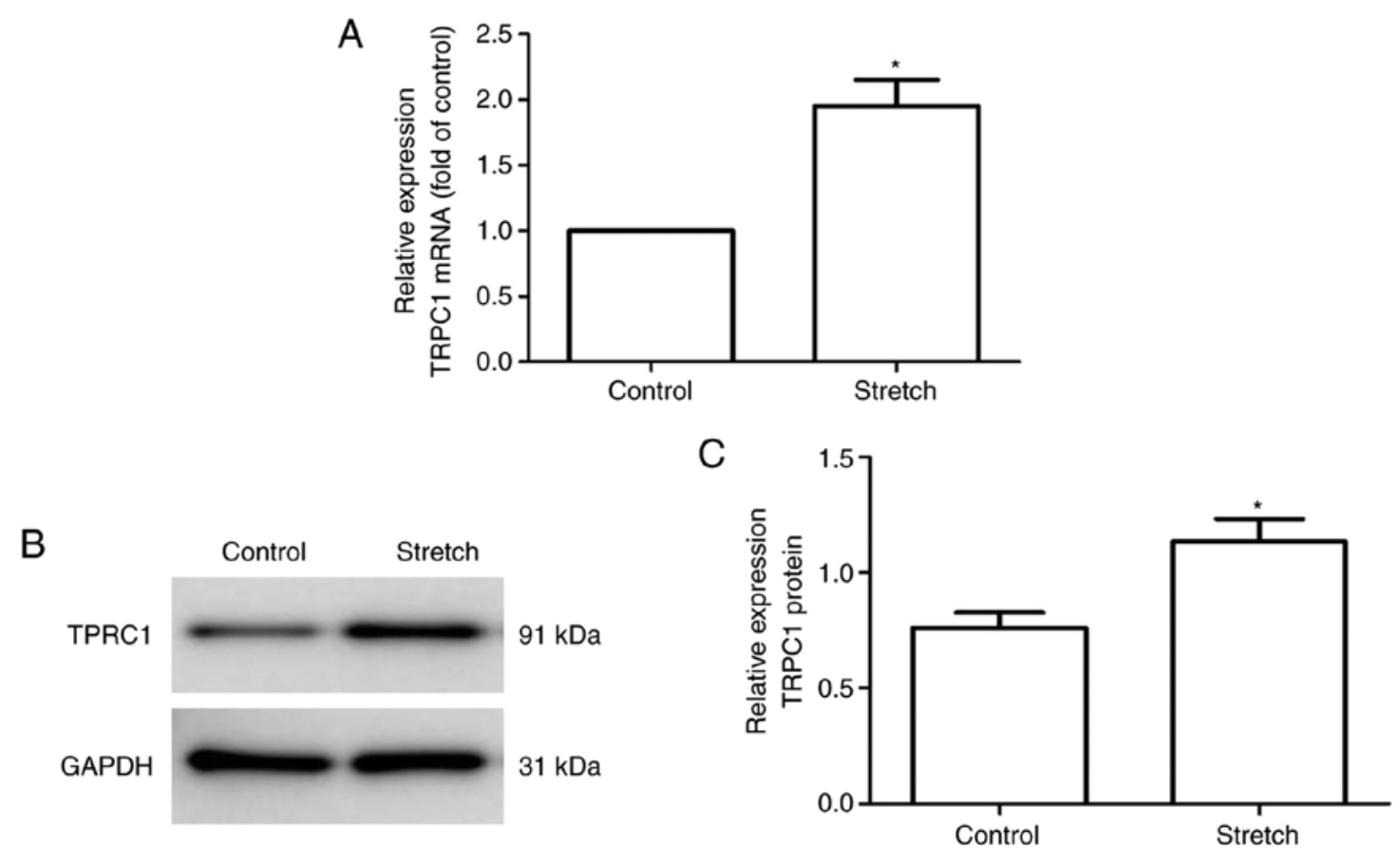

Figure 3. Effect of mechanical stretch on TRPC1 expression in 16HBE cells was determined by RT-qPCR and western blot analysis. (A) The mRNA level of the TRPC1 was determined by real-time RT-PCR. (B and C) The level of TRPC1 protein was determined by western blot analysis. Values in (A and C) are shown as the means $\pm \mathrm{SD}(\mathrm{n}=3) .{ }^{*} \mathrm{P}<0.05$ vs. the control group.

mechanical stretch substantially enhanced both the mRNA and protein levels of $\alpha$-SMA and attenuated the mRNA and protein levels of cytokeratin 8 and E-cadherin $(\mathrm{P} \leq 0.001)$. Additionally, these changes were significantly attenuated by transfection with TRPC1 siRNA $(\mathrm{P} \leq 0.001)$. However, transfection with NC siRNA did not alter the immunofluorescence intensity, mRNA or protein levels of cytokeratin 8 , E-cadherin or $\alpha$-SMA $(\mathrm{P} \geq 0.069)$.

The $\mathrm{Ca}^{2+}$ imaging results revealed that mechanical stretch induced an increase in intracellular $\mathrm{Ca}^{2+}$ levels. To further explore the role of intracellular $\mathrm{Ca}^{2+}$ in the expression of EMT markers under the condition of mechanical stretch, an 

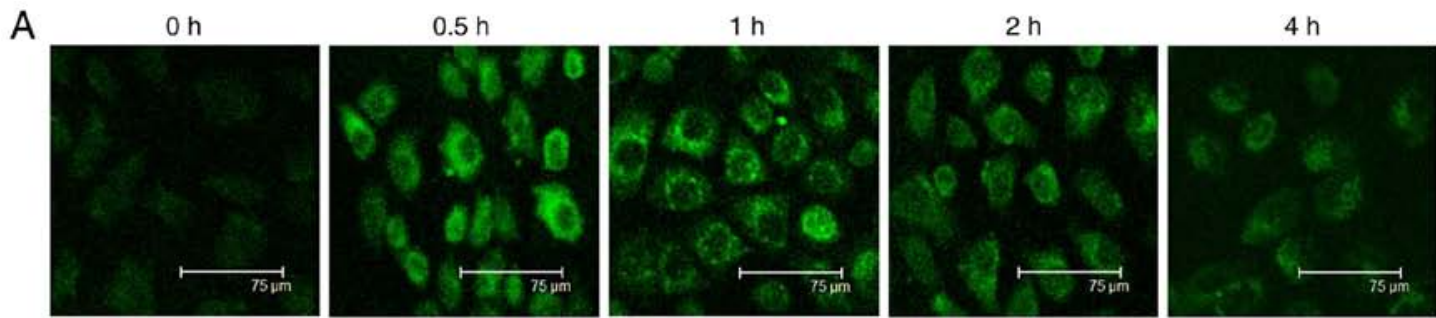

$8 \mathrm{~h}$

$12 \mathrm{~h}$
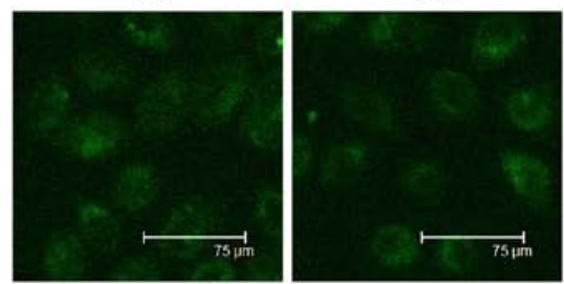

$24 \mathrm{~h}$
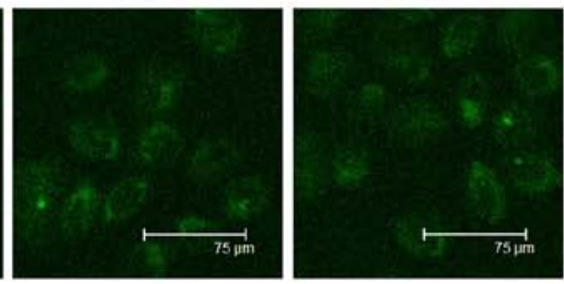

B

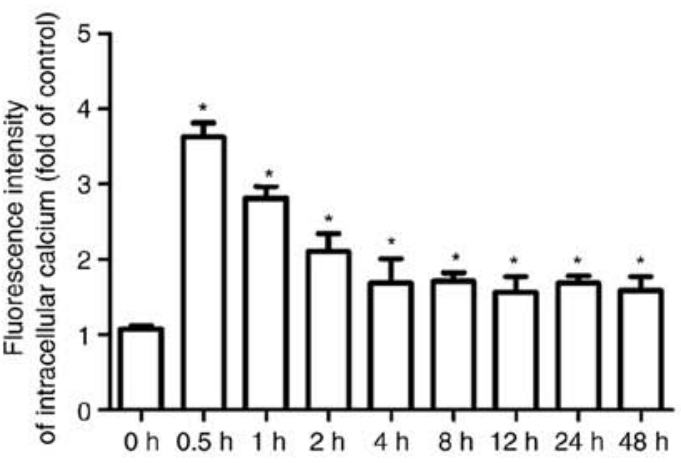

C

Control

Stretch

Stretch+TPRC1 siRNA

Stretch + NC siRNA
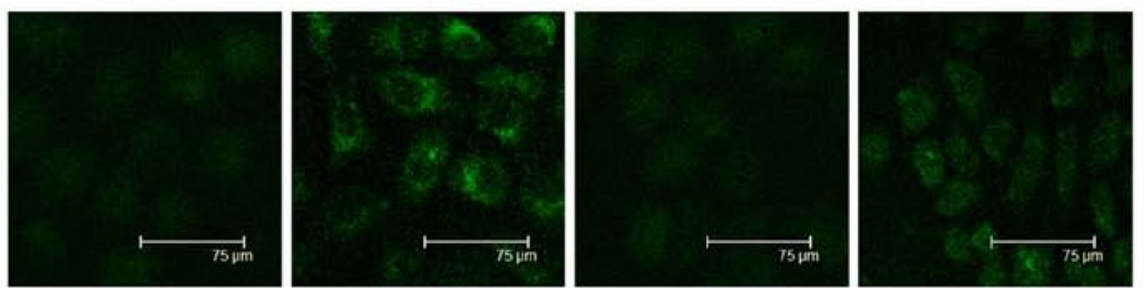

D

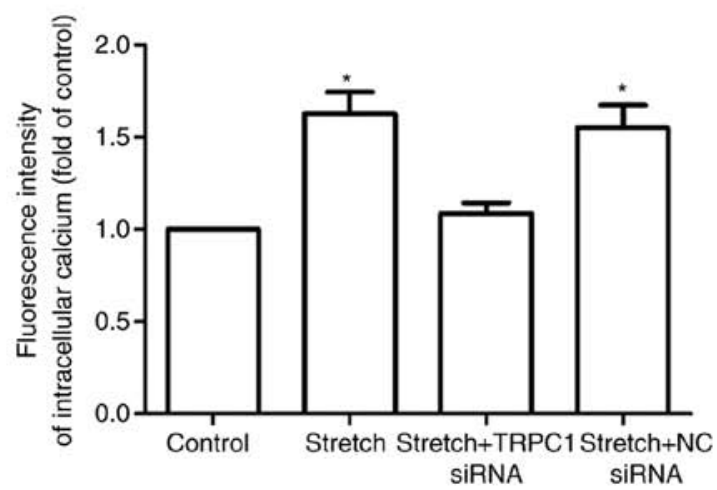

Figure 4. Fluorescence intensity of intracellular $\mathrm{Ca}^{2+}$ levels in $16 \mathrm{HBE}$ cells was determined using laser confocal microscopy. (A) Representative images of fluorescence-positive cells stretched for $0,0.5,1,2,4,8,12,24$ and $48 \mathrm{~h}$ at $15 \%$ elongation respectively. (B) The fluorescence intensities for intracellular $\mathrm{Ca}^{2+}$ levels in (A) were analyzed with the quantification tools and were shown by fold of control. (C) Representative images of fluorescence-positive cells stretched for $48 \mathrm{~h}$ at $15 \%$ elongation with or without transfection of TRPC1 siRNA or NC siRNA. (D) The fluorescence intensities for intracellular $\mathrm{Ca}^{2+}$ in (C) were analyzed with the quantification tools and are shown as the fold of the control. Values in (B and D) are shown as means $\pm \mathrm{SD}(\mathrm{n}=3)$. " $\mathrm{P}<0.05$ vs. the control group.

inhibitory experiment was also performed by the addition of the intracellular $\mathrm{Ca}^{2+}$ chelator, BAPTA-AM. As shown in Fig. 5, changes in immunofluorescence intensity, and in the
mRNA and protein levels of cytokeratin 8, E-cadherin and $\alpha$-SMA induced by mechanical stretch were markedly attenuated by BAPTA-AM $(\mathrm{P}<0.001)$. 
A

Cytokeratin 8

E-cadherin

$\alpha$-SAM

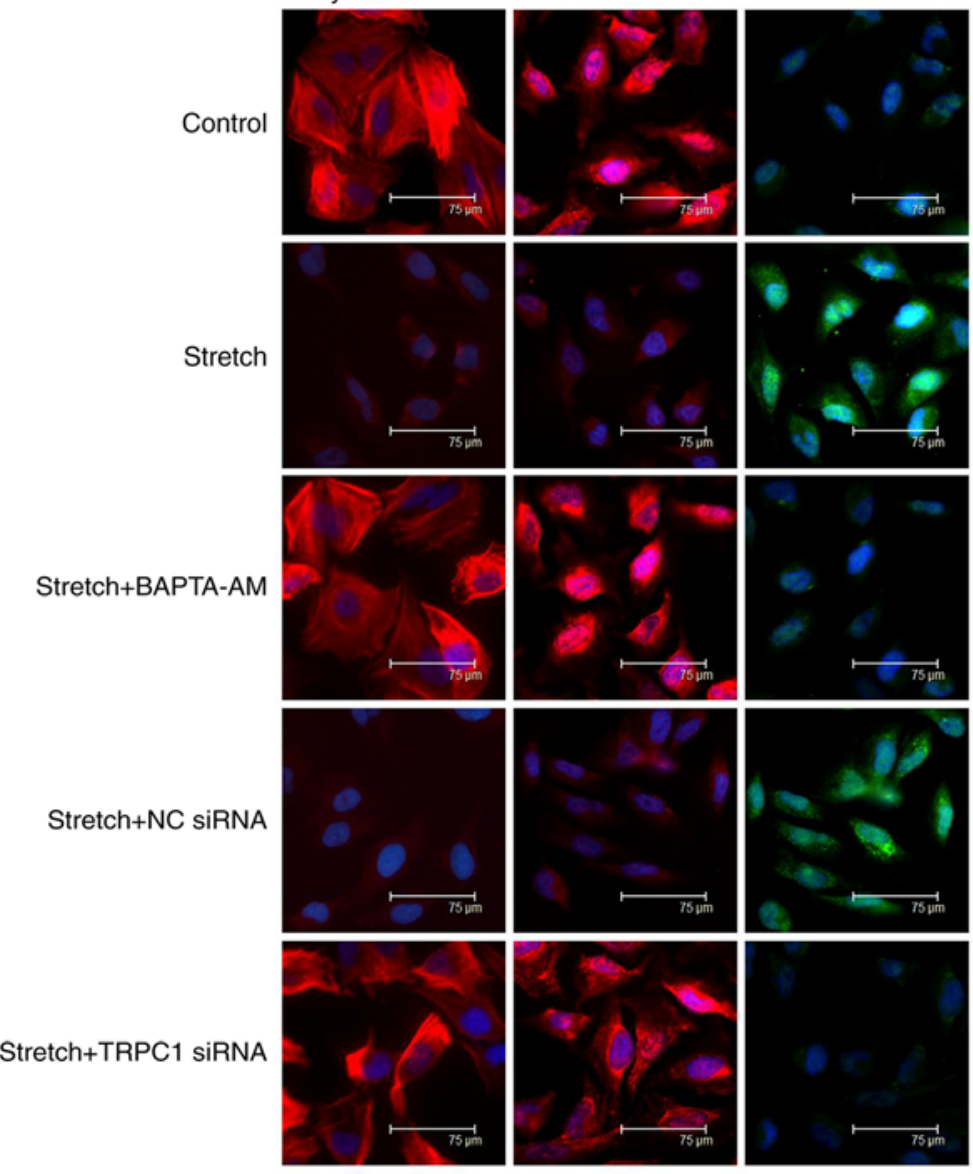

B
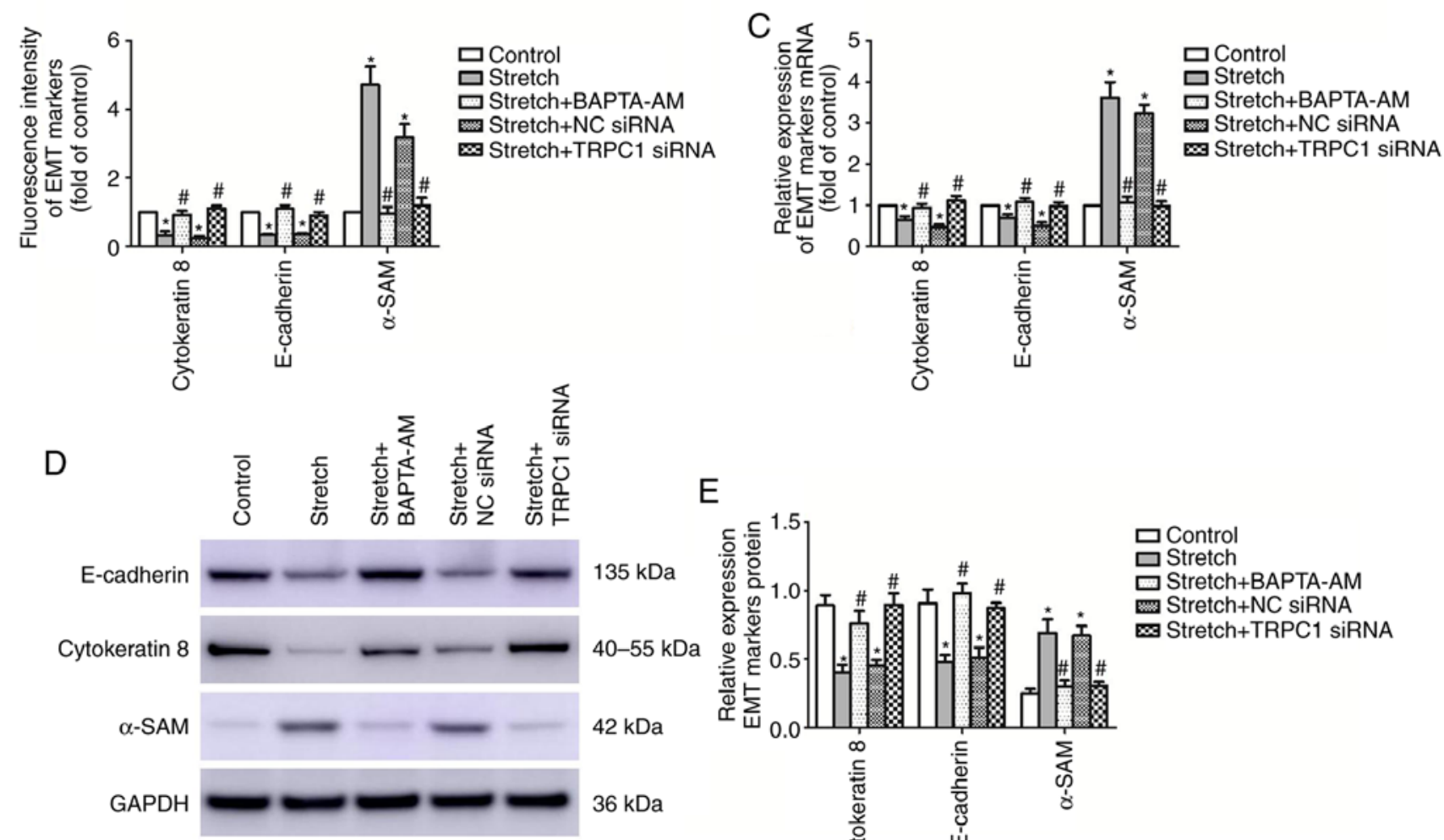

$\mathrm{E}$

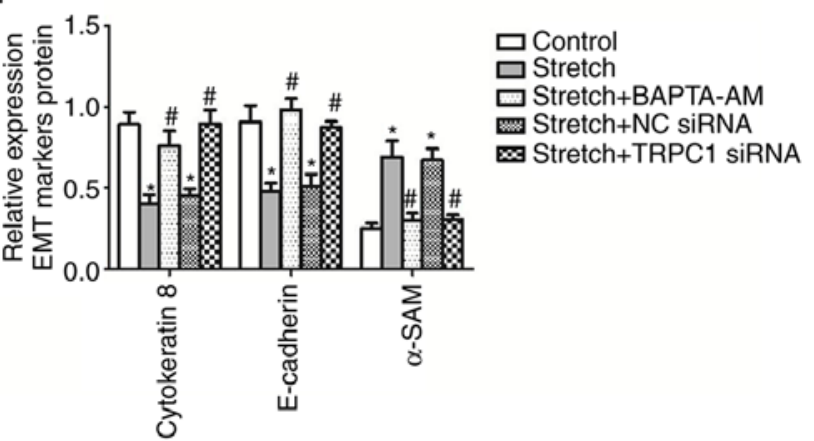

Figure 5. Epithelial-mesenchymal transition (EMT) markers in 16HBE cells after stretching with $15 \%$ elongation for $48 \mathrm{~h}$ were determined using immunofluorescence, RT-qPCR and western blot analysis. (A) Representative images of fluorescence-positive cells stretched for $48 \mathrm{~h}$ at $15 \%$ elongation. (B) The fluorescence intensities for EMT markers were analyzed with the quantification tools and were shown by fold of control. (C) The levels of the EMT markers mRNA were determined using real-time RT-qPCR. (D and E) The protein levels of the EMT-related markers were determined by western blot analysis. Values in $(B, C$ and $E)$ are shown as the means $\pm \mathrm{SD}(n=3) .{ }^{*} \mathrm{P}<0.05$ vs. the control group. ${ }^{~} \mathrm{P}<0.05$ vs. the stretch group. 


\section{Discussion}

In the present study, it was observed that the expression of TRPC1 was increased in airway epithelial cells in patients with COPD. In vitro, a Flexcell FX-4000 Tension System was used to stretch the 16HBE cells at a $15 \%$ elongation to imitate the pathological increased airway mechanical pressure in COPD. The decreased expression of cytokeratin 8 and E-cadherin and the simultaneous increase in the expression of $\alpha$-SMA supported the occurrence of EMT. Furthermore, the mechanisms underlying these changes was mediated, at least in part, by a TRPC1-mediated intracellular $\mathrm{Ca}^{2+}$ increase since transfection with TRPC1 siRNA or treatment with intracellular $\mathrm{Ca}^{2+}$ chelator BAPTA-AM abolished these alterations in EMT marker expression induced by mechanical stress. These results may thus provide a novel mechanistic insight into the treatment or alleviation of airway remodeling in COPD.

Cells and the ECM in the lung exist in a mechanically dynamic environment. Mechanical stretch is essential for the regulation of respiratory physiology and pathophysiology. Pathologically increased mechanical stretch exerted on lung tissues is one of the most common characteristics of chronic inflammatory airway diseases, such as COPD and asthma due to bronchoconstriction, mucus hypersecretion and airway remodeling. In turn, increased mechanical stretch has been reported to increase goblet cell number and MUC5AC protein expression (5), upregulate the expression levels of IL-13, transforming growth factor (TGF- $\beta 1$ ) and MMP-9 in bronchial epithelial cells (2), finally further aggravating mucus hypersecretion as well as airway remodeling in these conditions. Thus, a better understanding of the mechanisms through which how lung cells respond to mechanical stretch is of key importance for identifying targets for the treatment and prevention of chronic inflammatory airway diseases.

Mechanotransduction is a fundamental process of the conversion of mechanical stimuli into biochemical or/and electrical signals $(26,27)$. This phenomenon is widely studied in several areas of medical science, including vascular biology $(6,28,29)$ and skeletal biology $(7,30)$. It has been proposed that a number of TRP isoforms exhibit mechanosensitivity (TRPA1; TRPV1, 2, 4; TRPC1, 5, 6; TRPM3, 7; TRPP2) $(31,32)$. Among these, TRPC1 was the first cloned TRP channel (33) and exhibited high mechanosensitivity in vertebrates (22). It is widely present in the heart, arteries, skeletal muscle and was reported to be plentifully expressed in airway epithelial cells and show a significant increase in patients with COPD (18). Previous studies have demonstrated that mechanical stretch can induce an influx in $\mathrm{Ca}^{2+}$ levels and can upregulate the expression of airway remodeling-associated factors, IL-13, MMP-9 and TGF- $\beta 1$ in the 16HBE cells via the activation of TRPC1, indicating its critical role in mechanical stretch induced airway remodeling $(2,8)$.

Currently, the EMT mechanism for human airway remodeling in COPD has attracted the attention of various researchers. Emerging evidence suggests that primary human lung epithelial cells subjected to mechanical stretch develop EMT phenotypes $(19,20,34)$; Xu et al recently reported that a high expression of TRPC1 in the airway epithelia of patients with COPD was accompanied by an increased level of vimentin and a simultaneously decreased level of E-cadherin, as well as morphological changes from a typical epithelial cobblestone appearance with close connection to a more loosely connected elongated fusiform appearance, demonstrating its role in occurrence of EMT in COPD (18). Given the mechanosensitive properties of TRPC 1 and the fact that TRPC1 overexpression in COPD promoted EMT process, the present study investigated the role of TRPC1 in the occurrence of COPD-associated EMT in response to mechanical stress. The results demonstrated that TRPC1-mediated intracellular $\mathrm{Ca}^{2+}$ increase plays an important role in this process.

As a well-established mechanosensitive, $\mathrm{Ca}^{2+}$-permeable TRP channels (35), the activation of TRPC1 depends on both phosphatidylinositol-4,5-bisphosphate $\left(\mathrm{PIP}_{2}\right)$ and protein kinase $\mathrm{C}$ (PKC) (36). The intracellular $\mathrm{Ca}^{2+}$ increase following TRPC1 activation can activate phospholipase C(PLC), which subsequently hydrolyze $\mathrm{PIP}_{2}$, generating inositoltrisphosphate (IP3) and diacylglycerol (DAG). DAG can activate PKC, and IP3 may bind to its calcium channel-coupled receptor on the ER membrane and induce $\mathrm{Ca}^{2+}$ release from endoplasmic reticulum (37). Thus, it was hypothesized that the intracellular $\mathrm{Ca}^{2+}$ increase observed in the present study may result from both an influx of extracellular $\mathrm{Ca}^{2+}$ and $\mathrm{Ca}^{2+}$ release from the ER, and the reduced level of $\mathrm{PIP}_{2}$ and the simultaneous increase of PKC may explain the plateau of the intracellular calcium concentration when exposed to chronic mechanical stress. However, further studies are required to address these issues.

Studies on in vitro alveolar epithelial cell cultures using mechanical stretch suggest that a 5 to $12 \%$ elongation is physiological, while mechanical stretch at 37 to $50 \%$ elongation is associated with pathophysiological conditions produced by mechanical ventilation $(34,38,39)$. Therefore, in the present study, a $15 \%$ elongation for $48 \mathrm{~h}$ was used as a stimulus for $16 \mathrm{HBE}$ cells. This magnitude of stimulation and timing likely reflects the pathologic conditions of chronic airway diseases such as COPD.

A higher TRPC1 expression was observed level in the lung tissues of patients with COPD compared with those of the control group, which was consistent with the findings of a previous study (18). It has previously been reported that $5 \%$ CSE for $48 \mathrm{~h}$ significantly increased TRPC1 protein expression in $16 \mathrm{HBE}$ cells (18), and nicotine treatment obviously upregulated TRPC1 expression in cultured rat distal pulmonary arterial smooth muscle (PASMCs) (40), indicating a role of cigarette smoke in upregulation of TRPCl expression. However, Jiang et al found no significant difference in TRPC1 expression between patients with NSCLC who were smokers and non-smokers (41). Thus, it is currently not clear whether the upregulation of TRPClin COPD is due to cigarette smoke or other factors associated with COPD.

In conclusion, the present study demonstrated that the TRPC1-mediated increase in intracellular $\mathrm{Ca}^{2+}$ levels play a key role in mechanical stress-induced occurrence of EMT. There were some limitations to the present study. First, the possible involved signaling pathway downstream TRPC1-mediated intracellular $\mathrm{Ca}^{2+}$ in EMT occurrence induced by mechanical stretch was not investigated. Second, in the present study, 16HBE cells subjected to a Flexcell FX-4000 Tension System used to mimic the effects of high airway pressure. This model may not fully reflect the in vivo condition, where other cell types are present as well. In addition, primary normal human 
bronchial epithelial (NHBE) cells may be more suitable since they were established without any genetic background changes (42). Therefore, further studies are required to address these questions thoroughly, which will aid in the elucidation of the mechanisms of mechanical stretch-induced airway remodeling in COPD and may provide a novel therapeutic target for patients with COPD.

\section{Acknowledgements}

Not applicable.

\section{Funding}

The present study was funded by the National Natural Science Foundation of China (grant no. 81270102), the National Natural Science Foundation of Chongqing (grant no. cstc2019jcyj-msxmX0849) and the Joint Fund of science and health Medicine of Chongqing, China (grant no. 2019QNXM004).

\section{Availability of data and materials}

The analyzed data sets generated during the present study are available from the corresponding author on reasonable request.

\section{Authors' contributions}

ML and MZ designed the research; JW wrote the manuscript and analyzed data, YH, NL and GY performed the research and analyzed data. All authors read and approved the final manuscript.

\section{Ethics approval and consent to participate}

Ethics committee approval was obtained for the Second Clinical Hospital of Chongqing Medical University [reference no. 2014(65)], and all subjects provided written informed consent.

\section{Patient consent for publication}

Not applicable.

\section{Competing interests}

The authors declare that they have no competing interests.

\section{References}

1. Garcia CS, Prota LF, Morales MM, Romero PV, Zin WA and Rocco PR: Understanding the mechanisms of lung mechanical stress. Braz J Med Biol Res 39: 697-706, 2006.

2. Yu Q and Li M: Effects of transient receptor potential canonical 1 (TRPC1) on the mechanical stretch-induced expression of airway remodeling-associated factors in human bronchial epithelioid cells. J Biomech 51: 89-96, 2017.

3. Birukova AA, Tian Y, Meliton A, Leff A, Wu T and Birukov KG: Stimulation of Rho signaling by pathologic mechanical stretch is a 'second hit' to Rho-independent lung injury induced by IL-6. Am J Physiol Lung Cell Mol Physiol 302: L965-L975, 2012.

4. Park JA and Tschumperlin DJ: Chronic intermittent mechanical stress increases MUC5AC protein expression. Am J Respir Cell Mol Biol 41: 459-466, 2009.
5. Li N, Li Q, Zhou XD, Kolosov VP and Perelman JM: Chronic mechanical stress induces mucin $5 \mathrm{AC}$ expression in human bronchial epithelial cells through ERK dependent pathways. Mol Biol Rep 39: 1019-1028, 2012.

6. Tschumperlin DJ and Drazen JM: Mechanical stimuli to airway remodeling. Am J Respir Crit Care Med 164: S90-S94, 2001.

7. Suki B, Sato S, Parameswaran H, Szabari MV, Takahashi A and Bartolák-Suki E: Emphysema and mechanical stress-induced lung remodeling. Physiology (Bethesda) 28: 404-413, 2013.

8. Li N, He Y, Yang G, Yu Q and Li M: Role of TRPC1 channels in pressure-mediated activation of airway remodeling. Respir Res 20: 91, 2019.

9. Ito JT, Lourenço JD, Righetti RF, Tibério IFLC, Prado CM and Lopes FDTQS: Extracellular matrix component remodeling in respiratory diseases: What has been found in clinical and experimental studies? Cells 8: pii: E342, 2019.

10. Jones RL, Noble PB, Elliot JG and James AL: Airway remodelling in COPD: It's not asthma! Respirology 21: 1347-1356, 2016.

11. Pain M, Bermudez O, Lacoste P, Royer PJ, Botturi K, Tissot A, Brouard S, Eickelberg $\mathrm{O}$ and Magnan A: Tissue remodelling in chronic bronchial diseases: From the epithelial to mesenchymal phenotype. Eur Respir Rev 23: 118-130, 2014.

12. Kalluri R and Weinberg RA: The basics of epithelial-mesenchymal transition. J Clin Invest 119: 1420-1428, 2009.

13. Lamouille S, Xu J and Derynck R: Molecular mechanisms of epithelial-mesenchymal transition. Nat Rev Mol Cell Biol 15: 178-196, 2014.

14. Sohal SS, Reid D, Soltani A, Ward C, Weston S, Muller HK, Wood-Baker R and Walters EH: Reticular basement membrane fragmentation and potential epithelial mesenchymal transition is exaggerated in the airways of smokers with chronic obstructive pulmonary disease. Respirology 15: 930-938, 2010.

15. Sohal SS, Reid D, Soltani A, Ward C, Weston S, Muller HK, Wood-Baker R and Walters EH: Evaluation of epithelial mesenchymal transition in patients with chronic obstructive pulmonary disease. Respir Res 12: 130, 2011.

16. Gohy ST, Hupin C, Fregimilicka C, Detry BR, Bouzin C, Gaide Chevronay H, Lecocq M, Weynand B, Ladjemi MZ, Pierreux CE, et al: Imprinting of the COPD airway epithelium for dedifferentiation and mesenchymal transition. Eur Respir J 45: 1258-1272, 2015.

17. Milara J, Peiró T, Serrano A and Cortijo J: Epithelial to mesenchymal transition is increased in patients with COPD and induced by cigarette smoke. Thorax 68: 410-420, 2013.

18. Xu F, Liu XC, Li L, Ma CN and Zhang YJ: Effects of TRPC1 on epithelial mesenchymal transition in human airway in chronic obstructive pulmonary disease. Medicine (Baltimore) 96: e8166, 2017.

19. Heise RL, Stober V, Cheluvaraju C, Hollingsworth JW and Garantziotis S: Mechanical stretch induces epithelial-mesenchymal transition in alveolar epithelia via hyaluronan activation of innate immunity. J Biol Chem 286: 17435-17444, 2011.

20. Mao P, Li J, Huang Y, Wu S, Pang X, He W, Liu X, Slutsky AS, Zhang Hand Li Y: MicroRNA-19b mediates lung epithelial-mesenchymal transition via phosphatidylinositol-3,4,5-trisphosphate 3-phosphatase in response to mechanical stretch. Am J Respir Cell Mol Biol 56: 11-19, 2017.

21. Yang Y, Hu L, Xia H, Chen L, Cui S, Wang Y, Zhou T, Xiong W, Song L,Li S, et al: Resolvin D1 attenuates mechanical stretch-induced pulmonary fibrosis via epithelial-mesenchymal transition. Am J Physiol Lung Cell Mol Physiol 316: L1013-L1024, 2019.

22. Maroto R, Raso A, Wood TG, Kurosky A, Martinac B and Hamill OP: TRPC1 forms the stretch-activated cation channel in vertebrate cells. Nat Cell Biol 7: 179-185, 2005.

23. Banner KH, Igney F and Poll C: TRP channels: Emerging targets for respiratory disease. Pharmacol Ther 130: 371-384, 2011.

24. Global Initiative for Chronic Obstructive Lung Disease: Global strategy for the diagnosis, management, and prevention of chronic obstructive pulmonary disease 2019 report. https://goldcopd.org/ gold-reports/. Accessed December 2, 2018.

25. Livak KJ and Schmittgen TD: Analysis of relative gene expression data using real-time quantitative PCR and the 2(-Delta Delta C(T)) method. Methods 25: 402-408, 2001.

26. Gillespie PG and Walker RG: Molecular basis of mechanosensory transduction. Nature 413: 194-202, 2001.

27. Marshall KL and Lumpkin EA: The molecular basis of mechanosensory transduction. Adv Exp Med Biol 739: 142-155, 2012.

28. Humphrey JD, Schwartz MA, Tellides G and Milewicz DM: Role of mechanotransduction in vascular biology: Focus on thoracic aortic aneurysms and dissections. Circ Res 116: 1448-1461, 2015. 
29. Yin J and Kuebler WM: Mechanotransduction by TRP channels: General concepts and specific role in the vasculature. Cell Biochem Biophys 56: 1-18, 2010.

30. Burkholder TJ: Mechanotransduction in skeletal muscle. Front Biosci 12: 174-191, 2007.

31. Inoue R, Jian Z and Kawarabayashi Y: Mechanosensitive TRP channels in cardiovascular pathophysiology. Pharmacol Ther 123: 371-385, 2009.

32. Plant TD: TRPs in mechanosensing and volume regulation. Handb Exp Pharmacol 223: 743-766, 2014.

33. Nesin V and Tsiokas L: TRPC1. Handb Exp Pharmacol 222: 15-51, 2014.

34. Cabrera-Benítez NE, Parotto M, Post M, Han B, Spieth PM, Cheng WE, Valladares F, Villar J,Liu M,Sato M, et al: Mechanical stress induces lung fibrosis by epithelial-mesenchymal transition. Crit Care Med 40: 510-517, 2012.

35. Rychkov G and Barritt GJ: TRPC1 Ca(2+)-permeable channels in animal cells. Handb Exp Pharmacol: 23-52, 2007.

36. Albert AP: Gating mechanisms of canonical transient receptor potential channel proteins: Role of phosphoinositols and diacylglycerol. Adv Exp Med Biol 704: 391-411, 2011.

37. Bosanac I, Michikawa T, Mikoshiba K and Ikura M: Structural insights into the regulatory mechanism of IP3 receptor. Biochim Biophys Acta 1742: 89-102, 2004.

38. Letsiou E, Sammani S, Zhang W, Zhou T, Quijada H, Moreno-Vinasco L, Dudek SM and Garcia JG: Pathologic mechanical stress and endotoxin exposure increases lung endothelial microparticle shedding. Am J Respir Cell Mol Biol 52: 193-204, 2015
39. Suryadevara V, Fu P, Ebenezer DL, Berdyshev E, Bronova IA, Huang LS, Harijith A and Natarajan V: Sphingolipids in ventilator induced lung injury: Role of sphingosine-1-phosphate lyase. Int J Mol Sci 19: pii: E114, 2018.

40. Wang J, Chen Y, Lin C, Jia J, Tian L, Yang K, Zhao L, Lai N, Jiang Q, Sun Y, et al: Effects of chronic exposure to cigarette smoke on canonical transient receptor potential expression in rat pulmonary arterial smooth muscle. Am J Physiol Cell Physiol 306: C364-C373, 2014.

41. Jiang HN, Zeng B, Zhang Y, Daskoulidou N, Fan H, Qu JM and Xu SZ: Involvement of TRPC channels in lung cancer cell differentiation and the correlation analysis in human non-small cell lung cancer. PLoS One 8: e67637, 2013.

42. Feng W, Guo J, Huang H, Xia B, Liu H, Li J, Lin S, Li T, Liu J and Li H: Human normal bronchial epithelial cells: A novel in vitro cell model for toxicity evaluation. PLoS One 10: e0123520, 2015.

(i) (3) This work is licensed under a Creative Commons Attribution-NonCommercial-NoDerivatives 4.0 International (CC BY-NC-ND 4.0) License. 